\title{
Alpha-Mangostin Improves Cardiac Hypertrophy and Fibrosis and Associated Biochemical Parameters in High-Fat/High-Glucose Diet and Low-Dose Streptozotocin Injection-Induced Type 2 Diabetic Rats
}

\author{
Vivian Soetikno $\mathbb{D}^{\prime}$ \\ Andriyani Murwantara ${ }^{2}$ \\ Prisma Andini ${ }^{2}$ \\ Fabrian Charlie ${ }^{2}$ \\ Gilbert Lazarus $\mathbb{D D}^{3}$ \\ Melva Louisa $\mathbb{1}^{\prime}$ \\ Wawaimuli Arozal' \\ 'Department of Pharmacology and \\ Therapeutics, Faculty of Medicine, \\ Universitas Indonesia, Jakarta, 10430, \\ Indonesia; ${ }^{2}$ Graduate Course, Faculty of \\ Medicine, Universitas Indonesia, Jakarta \\ 10430, Indonesia; ${ }^{3}$ Undergraduate \\ Course, Faculty of Medicine, Universitas \\ Indonesia, Jakarta 10430, Indonesia
}

This article was published in the following Dove Press journal: Journal of Experimental Pharmacology

Purpose: The aim of present study was to analyze the effect of alpha-mangostin on cardiac hypertrophy and fibrosis and biochemical parameters in high-fat/high-glucose diet and lowdose streptozotocin injection (HF/HG/STZ)-induced type 2 diabetic rats.

Methods: Diabetes was induced in male Wistar rats by giving a combination of high-fat/highglucose $(\mathrm{HF} / \mathrm{HG})$ diet for 3 weeks and followed by low-dose streptozotocin intraperitoneal injection (STZ; $35 \mathrm{mg} / \mathrm{kg}$ ) at Week-3 and the HF/HG diet was continued until 8 weeks. The diabetic rats were then divided into four groups (each, $n=6)$ : untreated diabetic group $(\mathrm{HF} / \mathrm{HG} /$ STZ); diabetic group treated with metformin $200 \mathrm{mg} / \mathrm{kg} /$ day (HF/HG/STZ+Metformin); diabetic group treated with alpha-mangostin $100 \mathrm{mg} / \mathrm{kg} / \mathrm{day}(\mathrm{HF} / \mathrm{HG} / \mathrm{STZ}+\mathrm{AM} 100)$; and diabetic group treated with alpha-mangostin $200 \mathrm{mg} / \mathrm{kg} /$ day $(\mathrm{HF} / \mathrm{HG} / \mathrm{STZ}+\mathrm{AM} 200)$ and all were given by oral gavage for 8 weeks. We also included a control group (C) treated with AM200 (C+AM200). The role of alpha-mangostin was assessed through its effect on blood glucose levels, HOMA-IR, blood pressure, body weight, pro-inflammatory cytokines in cardiac tissue, serum aminotransferases (ALT and AST), lipid profiles (cholesterol and triglyceride), blood urea nitrogen (BUN), uric acid, cardiac hypertrophy and fibrosis.

Results: Diabetic rats treated with alpha-mangostin in both doses for 8 weeks showed decrease in blood glucose levels, HOMA-IR, and blood pressure. Alpha-mangostin treatment also prevented $\mathrm{HF} / \mathrm{HG} / \mathrm{STZ}$-induced changes in the activities of ALT, AST, BUN, uric acid, lipid profiles, and proinflammatory cytokines, which were comparable with the standard drug metformin, while alphamangostin did not show any significant effects on control rats $(p>0.05)$. The cardiac hypertrophy and fibrosis were also attenuated in diabetic rats treated with alpha-mangostin in both doses.

Conclusion: These data suggest that administration of alpha-mangostin can effectively attenuate diabetes-induced alteration in cardiac hypertrophy and fibrosis as well as biochemical parameters in $\mathrm{HF} / \mathrm{HG} / \mathrm{STZ}$ rats.

Keywords: insulin resistance, diabetes mellitus, hyperinsulinemia, hyperglycemia, cardiomyopathy, dietary fats

\section{Introduction}

Type 2 diabetes mellitus (T2DM) is a non-communicable metabolic disorder that is characterized by insulin resistance and disruption of pancreatic beta cells which ultimately causes hyperglycemia. ${ }^{1,2}$ Chronic hyperglycemia caused by uncontrolled
Correspondence: Vivian Soetikno Tel +62 2131930481

Email vivian.soetikno@ui.ac.id 
diabetes will cause microvascular and macrovascular complications which will ultimately cause organ damage, especially in the cardiovascular system. ${ }^{3}$ Besides hyperglycemia, several other factors such as dyslipidemia, hyperuricemia, and increased serum transaminases are also involved in the development of cardiovascular complications in diabetes. ${ }^{4-6}$ Pathophysiology of an increased cardiovascular complication in diabetes include (1) patient with diabetes have a high incidence of coronary artery disease and atherosclerotic lesions at a young age; (2) hypertension often occurs in patients with type 1 and 2 diabetes; and (3) diabetes can cause pathological changes in myocardium, which is often referred to as diabetic cardiomyopathy, which is independent of hypertension and coronary atherosclerosis. $^{7,8}$ To date, diabetic cardiomyopathy has become one of the main reasons of increased morbidity and mortality in diabetic patients.

Control of blood glucose levels in diabetic patients is very important, considering this can prevent complications in diabetes. Lifestyle changes and diet are very important initial steps to control blood glucose levels. ${ }^{9}$ In addition, conventional drugs can also control blood glucose levels, but the side effects that sometimes cause patients to stop treatment have attracted attention to develop safer treatments from medicinal plants. ${ }^{10}$

According to World Health Organization (WHO), medicines derived from plants are very effective in managing diabetes and also rarely cause side effects, in addition to the low cost when compared to conventional drugs. ${ }^{11}$ In accordance with WHO's statement, in 1998 the Indonesian Minister of Health also released a statement "Back to Nature Used Indonesian Traditional Medicine" to overcome problems caused by diabetes and was stipulated in Centers for development and application of traditional medicine. ${ }^{12}$ In this context, the medicinal plant Garcinia mangostana, commonly known as mangosteen, is a slowgrowing tropical tree and is commonly found in tropical countries such as Indonesia, India, Thailand, and Myanmar. The pericarp of mangosteen has been used in Indonesia as a cholesterol-lowering agent, and we have observed that the active compound of mangosteen's pericarp (alpha-mangostin) has anticancer and antifibrosis activities. $^{13,14}$ Moreover, alpha-mangostin is also known to have anti-oxidant, anti-inflammatory, hypo-allergenic, and antifungal activities. ${ }^{15,16}$ However, to the best of our knowledge, it is not yet known whether alpha-mangostin can prevent cardiac hypertrophy and fibrosis due to diabetes. Therefore, the aim of this study was to evaluate the possible protective effects of alpha-mangostin on cardiac hypertrophy and fibrosis and associated biochemical parameters in rats with high-fat/high-glucose and low-dose streptozotocin-induced T2DM.

\section{Materials and Methods Materials}

Alpha-mangostin was purchased from Aktin Chemicals, Inc., Chengdu, China (batch \#AM-170622 and $\geq 98 \%$ purity with HPLC method). Streptozotocin was purchased from Santa Cruz, USA (catalog \# sc-200719A). All other chemicals and solvents were of analytical grade and procured from Sigma-Aldrich, Indonesia.

\section{Animals}

Male Wistar rats, 150 to $250 \mathrm{~g}$ body weight, were purchased from Laboratory Animal Center of Litbangkes, Indonesia and were housed in polypropylene cages in a room maintained at $23 \pm 2{ }^{\circ} \mathrm{C}$ with a $12 \mathrm{~h}$ light-dark cycle. Animal studies were conducted according to the Institute of Animal Studies Ethics Committee regulations approved by Faculty of Medicine, Universitas Indonesia (ethical clearance $\# 0084 / \mathrm{UN} 2 . F 1 / E T I K / 2018$ ) and all efforts were made to minimize suffering.

\section{Experimental Procedure}

The High-fat (HF) diet (TestDiet, $58 \mathrm{~V} 8$ rat chow, Richmond, USA) containing $46.1 \mathrm{wt} \%$ fat, $35.8 \mathrm{wt} \%$ carbohydrate, and $18.1 \mathrm{wt} \%$ protein, with a total energy $4.60 \mathrm{kcal} / \mathrm{g}$ along with $20 \%$ high-glucose (HG) drinking water was orally fed to animals for 3 weeks to induce type 2 diabetes mellitus. After 3 weeks of dietary manipulation, animals were injected intraperitoneally with lowdose streptozotocin (STZ) (35 mg/kg), prepared freshly by STZ dissolving in $0.01 \mathrm{M}$ citrate buffer, $\mathrm{pH} 4.5$. Fasting blood glucose levels were measured in 72 $\mathrm{h}$ after STZ administration, and those rats with fasting blood glucose concentration $\geq 250 \mathrm{mg} / \mathrm{dL}$ were included in the study. STZ injection can be repeated once with a half-dose of the initial dose, if the blood glucose level has not reached the target. Thereafter, the animals were fed $\mathrm{HF}$ and $\mathrm{HG}$ for another 8 weeks. Throughout the experiment, animals were weighted weekly and postprandial glycaemia was measured using Glucometer 4 Accu-check, CA. 


\section{Experimental Groups}

A total of 36 animals were divided into six groups of six animals in each. Group I, normal control (received $0.5 \mathrm{~mL}$ of distilled water); Group II, normal control received alpha-mangostin $(200 \mathrm{mg} / \mathrm{kg} /$ day $)$ dissolved in $1 \mathrm{~mL}$ of corn oil for 8 weeks by gavage; Group III, untreated type 2 diabetic animals; Group IV, type 2 diabetic animals received metformin $(200 \mathrm{mg} / \mathrm{kg} /$ day $)$ dissolved in $1 \mathrm{~mL}$ of $0.5 \%$ carboxymethylcellulose for 8 weeks by gavage; Group V, type 2 diabetic animals received alphamangostin $(100 \mathrm{mg} / \mathrm{kg} /$ day $)$ dissolved in $1 \mathrm{~mL}$ of corn oil for 8 weeks by gavage; Group VI, type 2 diabetic animals received alpha-mangostin $(200 \mathrm{mg} / \mathrm{kg} /$ day $)$ dissolved in $1 \mathrm{~mL}$ of corn oil for 8 weeks by gavage.

\section{Biochemical Assay and Blood Pressure Measurements}

At the end of experimental period (11 weeks), the animals were fasted overnight (12 h), anesthetized with ketamine/ xylazine $0.15 \mathrm{~mL} / 100 \mathrm{~g}$ body weight, i.p. and euthanized by cervical dislocation. The blood was collected and the serum was taken using tubes then centrifuged at $1000 \mathrm{~g}, 10 \mathrm{~min}, 4^{\circ} \mathrm{C}$ and used for biochemical analysis. Serum glucose, total cholesterol, triglyceride, uric acid, creatinine, alanine aminotransferase (ALT), aspartate aminotransferase (AST), were measured using the respective spectrophotometric diagnostic kit obtained from Biosino Biotechnology Company Ltd. (Beijing, PR China). Serum creatine kinase-muscle brain (CK-MB) and lactate dehydrogenase (LDH) were also examined using a kit from DiaSys Diagnostic Systems $\mathrm{GmbH}$ (Holzheim Germany) and read using a UV/VIS spectrophotometer (PerkinElmer). Insulin was measured with rat-specific ELISA kit (Mercodia, Uppsala, Sweden; Linco Research, St Charles, MO, USA). The HOMA index (homeostasis model assessment-insulin resistance) was determined using the steady-state blood glucose and insulin concentrations and was calculated as follows: HOMA-IR = blood glucose $(\mathrm{mM}) \mathrm{x}$ insulin $(\mu \mathrm{U} / \mathrm{L}) / 22.5 .{ }^{17}$ The spectrophotometric analysis was performed using a UV-Vis Optizen. Blood pressure was measured by indirect tail cuff method using CODA noninvasive blood pressure system (tail-cuff method, Kent Scientific Corporation). Three consecutive blood pressure measurements, which had a difference of less than 5 $\mathrm{mmHg}$, were considered as valid. Those measurements were averaged and their means taken as values of blood pressure at each time.

\section{Histological Analysis}

The samples of heart tissue were fixed with $4 \%$ paraformaldehyde for $24 \mathrm{~h}$, then embedded in paraffin, and sectioned into $4 \mu \mathrm{m}$ thick samples. The heart was then examined histopathologically through light microscopy using two different stains, namely hematoxylin and eosin (H\&E) and Masson's trichrome to analyze fibrosis.

\section{RT-PCR Analysis}

Total RNA was extracted from heart tissue using High Pure RNA Isolation kit (Roche Applied Science, Penzberg, Germany) and the RNA concentrations were determined by UV spectrophotometry at a wavelength of $260 \mathrm{~nm}$. A total of $1 \mu \mathrm{g}$ RNA of each sample was reverse transcribed using Transcriptor First Strand cDNA Synthesis kit (Roche Applied Science). Real-time PCR was performed using the Light Cycler instrument with LightCycler $^{\circledR} 480$ Instrument (Roche Applied Science) with FastStart Essential DNA Green Master Mix (Roche Life Science). The results of this study were normalized to housekeeping gene $\beta$-actin. Primer sequences used in this study are listed as follows: TNF- $\alpha(\mathrm{F})$ : $5^{\prime}$-TCT ACT CCC AGG TTC TCT TCA-3'; (R): 5'-CTC CTG GTA TGA AAT GGC AAA TC-3', and $\beta$-actin (F): 5'-GCT GGa AGG TGG ACA GCG A-3'; (R): 5'-GGC ATC GTG ATG GAC TCC G-3'. The amplification condition of PCR was as follows (in a total volume of $20 \mu \mathrm{L}$ ): initial denaturation $95^{\circ} \mathrm{C}, 10 \mathrm{~min}$; denaturation $95^{\circ} \mathrm{C}, 30 \mathrm{sec}$; primer annealing $57^{\circ} \mathrm{C}, 1 \mathrm{~min}$; extention $72^{\circ} \mathrm{C}, 1 \mathrm{~min}$; and 40 cycles. qPCR data are analyzed using double delta $\mathrm{Ct}$ according to Livak Method. ${ }^{18}$

\section{Estimation of MCP-I, IL-I $\beta$ and IL-6 in Homogenized Heart}

To analyze the effect of alpha-mangostin on heart cytokines and MCP-1 in HF/HG/STZ-induced T2DM rats, sandwich-ELISA kit for MCP-1 (Elabscience catalog \#E-EL-R0633, USA) and sandwich-ELISA kit for IL-1 $\beta$ and IL-6 (Elabscience catalog \#E-EL-R0012 and \#E-ELR0015, USA) were performed to the manufacturers' instructions.

\section{Statistical Analysis}

Results were expressed as mean $\pm \mathrm{SD}$. One-way ANOVA was used for multiple group comparisons, and Tukey's test was used for post-hoc analysis. Differences with $p<0.05$ were considered significant. 


\section{Results}

Effect of HF/HG/STZ and Alpha-Mangostin on Body Weight, Left Ventricle Weights, Blood Pressure, Insulin Sensitivity Index, Plasma Glucose Concentration, and Serum

\section{Cardiac Biomarkers}

As shown in Table 1, the mean body weight of the HF/HG/ STZ-induced diabetic group was lower compared to the other groups. Alpha-mangostin administration did not affect body weight of control group. However, alphamangostin in both doses and metformin administration suppressed a reduction in body weight within the diabetic groups, though this effect was not significantly different among groups. LVW-to-BW ratio in $\mathrm{HF} / \mathrm{HG} / \mathrm{STZ}$-induced diabetic group was significantly higher than that of control and control treated with alpha-mangostin groups. Alphamangostin in both doses and metformin administration entirely prevented the $\mathrm{HF} / \mathrm{HG} / \mathrm{STZ}$-induced increased of LVW-to-BW ratio. We also showed that the administration of alpha-mangostin in both doses and metformin was able to prevent an increase in blood pressure induced by $\mathrm{HF}$ / HG/STZ. To assess insulin resistance and sensitivity, we used homeostasis model of assessment-IR (HOMA-IR). As demonstrated in Table 1, at the end of experimental period, HOMA-IR level was significantly higher in the $\mathrm{HF} / \mathrm{HG} / \mathrm{STZ}$ group as compared to those in the control and control-treated with alpha-mangostin groups. The administration of metformin and alpha-mangostin in both doses could increase the insulin sensitivity as shown in the decrease of HOMA-IR, significantly as compared to that of $\mathrm{HF} / \mathrm{HG} / \mathrm{STZ}$ group, which proved that alpha-mangostin can improve insulin sensitivity. The HF/HG/STZ-induced diabetic rats showed a significant increase in fasting plasma glucose as compared to the control and controltreated with alpha-mangostin groups. Administration of alpha-mangostin at a dose of 100 and $200 \mathrm{mg} / \mathrm{kg} / \mathrm{day}$ caused a significant decrease in fasting plasma glucose levels compared with HF/HG/STZ group towards the normal levels. In addition, administration of $\mathrm{HF} / \mathrm{HG} / \mathrm{STZ}$ leads to pronounced cardiac damage that was shown by elevated serum CK-MB and $\mathrm{LDH}$ compared to that of control and control-treated with alpha-mangostin groups. Administration of alpha-mangostin in both doses and metformin could significantly reduce the elevated CK-MB. LDH level has also been reduced by the administration of alpha-mangostin as well as metformin to near normal levels, though it did not reach significant level.

\section{Effect of HF/HG/STZ and Alpha-Mangostin on Liver and Renal Function Tests}

Table 2 shows activities of enzymes of liver cell injury, ALT and AST in liver. The HF/HG/STZ group showed significantly increased of ALT and AST, 5-fold and 2.2-fold, respectively, as compared to the control group, and these alterations appeared to be lessened by metformin and alphamangostin in both doses. To assess the renal function, we measured BUN, and uric acid in serum. Both BUN and uric acid were increased in the $\mathrm{HF} / \mathrm{HG} / \mathrm{STZ}$ group as compared

Table I Body Weight, Left Ventricle Weight, LVW/BW Ratio, and Insulin Sensitivity Index of Rats at the End of Experiment

\begin{tabular}{|c|c|c|c|c|c|c|}
\hline Variable & $\begin{array}{l}\text { Control }(n=6) \\
\text { Mean } \pm \text { SD }\end{array}$ & $\begin{array}{l}\text { Control + } \\
\text { AM200 }(n=6) \\
\text { Mean } \pm \text { SD }\end{array}$ & $\begin{array}{l}\text { HF/HG/STZ } \\
(n=6) \\
\text { Mean } \pm \text { SD }\end{array}$ & $\begin{array}{l}\text { HF/HG/STZ + } \\
\text { Metformin }(n=6) \\
\text { Mean } \pm \text { SD }\end{array}$ & $\begin{array}{l}\text { HF/HG/STZ + } \\
\text { AMI00 }(n=6) \\
\text { Mean } \pm \text { SD }\end{array}$ & $\begin{array}{l}\text { HF/HG/STZ + } \\
\text { AM200 }(n=6) \\
\text { Mean } \pm \text { SD }\end{array}$ \\
\hline Body weight (g) & $280 \pm 49.9$ & $273 \pm 45.09$ & $249.7 \pm 34.81$ & $284 \pm 42.17$ & $276.7 \pm 49.7$ & $255 \pm 22.46$ \\
\hline LV weight (g) & $0.70 \pm 0.04$ & $0.70 \pm 0.09$ & $0.72 \pm 0.16$ & $0.60 \pm 0.11$ & $0.62 \pm 0.08$ & $0.69 \pm 0.07$ \\
\hline LVW/BW (g/kg) & $2.63 \pm 0.47$ & $2.75 \pm 0.78$ & $2.97 \pm 0.8 I^{*}$ & $2.18 \pm 0.52^{* *}$ & $2.32 \pm 0.37^{\#}$ & $2.67 \pm 0.29^{\# \#}$ \\
\hline $\begin{array}{l}\text { Blood Pressure } \\
(\mathrm{mmHg})\end{array}$ & $115 \pm 12 / 89 \pm 12$ & $102 \pm 31 / 81 \pm 30$ & $144 \pm 7 / 107 \pm 5^{*}$ & $122 \pm 7 / 97 \pm 7^{* *}$ & $113 \pm 12 / 85 \pm 11^{\#}$ & $|3| \pm 8 / 10 \mid \pm 8^{\# \#}$ \\
\hline $\begin{array}{l}\text { Fasting plasma } \\
\text { glucose }(\mathrm{mg} / \mathrm{dL})\end{array}$ & $105.6 \pm 7.5$ & $105.2 \pm 7.9$ & $277.4 \pm 35^{*}$ & $133.6 \pm 27^{* *}$ & $147.8 \pm 39^{\#}$ & $124.8 \pm 49^{\# \#}$ \\
\hline Food intake (g/day) & $25 \pm 1.04$ & $24.5 \pm 1.1$ & $29 \pm 2.2$ & $27 \pm 2.1$ & $26 \pm 0.3$ & $25 \pm 1.2$ \\
\hline Insulin $(\mu \mathrm{U} / \mathrm{mL})$ & $4.59 \pm 0.2$ & $4.53 \pm 0.3$ & $5.78 \pm 0.9 *$ & $4.58 \pm 0.5^{* *}$ & $4.46 \pm 0.2^{\#}$ & $4.59 \pm 0.2^{\# \#}$ \\
\hline HOMA-IR & $1.20 \pm 0.11$ & $1.08 \pm 0.11$ & $2.21 \pm 0.67^{*}$ & $1.04 \pm 0.45^{* *}$ & $1.04 \pm 0.45^{\#}$ & $1.15 \pm 0.47^{\# \#}$ \\
\hline CK-MB (U/L) & $63.9 \pm 14$ & $46.4 \pm 9$ & $116.1 \pm 32 *$ & $72.7 \pm 9.3^{* *}$ & $31.9 \pm 17.5^{\#}$ & $34.6 \pm 10^{\# \#}$ \\
\hline LDH (U/L) & $237.6 \pm 38$ & $248.8 \pm 25$ & $300.8 \pm 32^{*}$ & $267.3 \pm 52$ & $240.6 \pm 59$ & $230.2 \pm 32$ \\
\hline
\end{tabular}

Notes: ${ }^{*} p<0.05 \mathrm{HF} / \mathrm{HG} / \mathrm{STZ}$ vs control and control-treated with alpha-mangostin. ${ }^{* *} p<0.05 \mathrm{HF} / \mathrm{HG} / \mathrm{STZ}$ vs HF/HG/STZ + Metformin. ${ }^{\#} p<0.05$ HF/HG/STZ vs HF/HG/ STZ + AM 100. ${ }^{\#} p<0.05 \mathrm{HF} / \mathrm{HG} / \mathrm{STZ}$ vs HF/HG/STZ + AM 200. Results are represented as mean \pm SD and were analyzed using one-way ANOVA followed by Tukey's post-hoc analysis. Values are considered significantly different at $p<0.05$. 
Table 2 Effect of Alpha-Mangostin on Liver Function Test and Renal Function Test of Rats at the End of II Weeks

\begin{tabular}{|c|c|c|c|c|c|c|}
\hline Variable & $\begin{array}{l}\text { Control }(n=6) \\
\text { Mean } \pm \text { SD }\end{array}$ & $\begin{array}{l}\text { Control + AM200 } \\
(n=6) \\
\text { Mean } \pm \text { SD }\end{array}$ & $\begin{array}{l}\text { HF/HG/STZ } \\
(n=6) \\
\text { Mean } \pm \text { SD }\end{array}$ & $\begin{array}{l}\text { HF/HG/STZ + } \\
\text { Metformin }(n=6) \\
\text { Mean } \pm \text { SD }\end{array}$ & $\begin{array}{l}\text { HF/HG/STZ + } \\
\text { AMI00 }(n=6) \\
\text { Mean } \pm \text { SD }\end{array}$ & $\begin{array}{l}\text { HF/HG/STZ + } \\
\text { AM200 }(n=6) \\
\text { Mean } \pm \text { SD }\end{array}$ \\
\hline ALT (mg/dL) & $15.17 \pm 1.52$ & $25.79 \pm 6.30$ & $75.17 \pm 8.36^{*}$ & $36.29 \pm 7.20 * *$ & $49.58 \pm 9.26^{\#}$ & $37.27 \pm 5.27^{\# \#}$ \\
\hline AST (mg/dL) & $32.55 \pm 4.21$ & $40.02 \pm 2.4$ & $74.56 \pm 6.75^{*}$ & $55.16 \pm 8.23 * *$ & $54.06 \pm 3.92^{\#}$ & $53.70 \pm 5.54^{\# \#}$ \\
\hline BUN (mg/dL) & $22.63 \pm 2.89$ & $25.91 \pm 4.61$ & $37.28 \pm 13.48^{*}$ & $17.01 \pm 1.69 * *$ & $16.65 \pm 6.14^{\#}$ & $22.07 \pm 5.31^{\# \#}$ \\
\hline Uric acid (mg/dL) & $1.7 \pm 0.13$ & $1.51 \pm 0.28$ & $6.59 \pm 0.09 *$ & $2.32 \pm 1.9$ & $4.43 \pm 1.8$ & $3.41 \pm 2.13$ \\
\hline
\end{tabular}

Notes: ${ }^{*} p<0.05 \mathrm{HF} / \mathrm{HG} / \mathrm{STZ}$ vs control and control-treated with alpha-mangostin. **p $<0.05 \mathrm{HF} / \mathrm{HG} / \mathrm{STZ}$ vs HF/HG/STZ + Metformin. ${ }^{*} p<0.05$ HF/HG/STZ vs HF/HG/ STZ + AM 100. ${ }^{\#}$ < $0.05 \mathrm{HF} / \mathrm{HG} / \mathrm{STZ}$ vs HF/HG/STZ + AM 200. Results are represented as mean \pm SD and were analyzed using one-way ANOVA followed by Tukey's post-hoc analysis. Values are considered significantly different at $p<0.05$.

to the control and control-treated with alpha-mangostin groups. Metformin and alpha-mangostin appeared to restore the altered renal function test in serum.

\section{Effect of HF/HG/STZ and Alpha-Mangostin on Serum Lipids}

As shown in Table 3, the total cholesterol and triglyceride were significantly higher in the $\mathrm{HF} / \mathrm{HG} / \mathrm{STZ}$ group than in the control and control-treated with alpha-mangostin groups. The total cholesterol was increased by 1.47 -fold, whereas the triglyceride was increased by 1.41 -fold as compared to the control group. The total cholesterol and the triglyceride were also increased by 1.4-fold and 1.2-fold, respectively, as compared to that of control-treated with alpha-mangostin. Interestingly, the administration of metformin lowered total cholesterol by $13 \%$ and triglyceride by $25 \%$, whereas the administration of alpha-mangostin significantly decreased the total cholesterol (29-30\%) and triglyceride (18-45\%) at a dose of $100 \mathrm{mg} / \mathrm{kg} /$ day and $200 \mathrm{mg} / \mathrm{kg} /$ day, respectively.

\section{Effect of HF/HG/STZ and Alpha-Mangostin on Heart Proinflammatory Cytokines}

We next examined the expression of proinflammatory cytokines, TNF-alpha, MCP-1, IL-6, and IL-1 $\beta$ in the heart tissues by qRT-PCR and ELISA analysis, respectively. There were a 3-fold increase in TNF-alpha (Figure 1A and B) and a 3.8-fold increase in MCP-1 (Figure 2A), a 2-fold increase in IL-I $\beta$ and L-6 (Figure 2B and C) expression in the HF/HG/ STZ group, and alpha-mangostin in both doses reduced the TNF-alpha gene expression by $39.16-83.75 \%$, whereas metformin administration reduced its expression by $68.75 \%$. Likewise, alpha-mangostin in both doses and metformin administration reduced the protein expression of MCP-1 by $68.9 \%$ and $35 \%$, respectively, reduced the protein expression of IL- $1 \beta$ by $50-58 \%$ and $48 \%$, respectively, and IL- 6 by $28-44 \%$ and $23 \%$, respectively.

\section{Effect of Alpha-Mangostin on Left Ventricle Cardiomyocyte Hypertrophy and Interstitial Fibrosis}

Figure 3A-F shown cardiomyocytes performed in hematoxylin and eosin staining. The cardiomyocyte hypertrophy as indicated by an increase in average cross-sectional diameter of cardiac myocytes was seen in the HF/HG/STZ group (Figure 3C) compared with that in control (Figure 3A) and control treated with alpha-mangostin (Figure 3B) groups. However, this increase was significantly reduced only in alpha-mangostin at a dose of $100 \mathrm{mg} / \mathrm{kg} /$ day (Figure 3E and G). Although the administration of alpha-mangostin at a dose of $200 \mathrm{mg} / \mathrm{kg} / \mathrm{day}$ and metformin was able to reduce cardiac hypertrophy due to

Table 3 Effect of Alpha-Mangostin on Lipid Plasma of Rats at the End of II Weeks

\begin{tabular}{|c|c|c|c|c|c|c|}
\hline Variable & $\begin{array}{l}\text { Control }(n=6) \\
\text { Mean } \pm \text { SD }\end{array}$ & $\begin{array}{l}\text { Control + } \\
\text { AM200 }(n=6) \\
\text { Mean } \pm \text { SD }\end{array}$ & $\begin{array}{l}\text { HF/HG/STZ } \\
(n=6) \\
\text { Mean } \pm \text { SD }\end{array}$ & $\begin{array}{l}\text { HF/HG/STZ + } \\
\text { Metformin }(n=6) \\
\text { Mean } \pm \text { SD }\end{array}$ & $\begin{array}{l}\text { HF/HG/STZ + } \\
\text { AMI00 }(n=6) \\
\text { Mean } \pm \text { SD }\end{array}$ & $\begin{array}{l}\text { HF/HG/STZ + } \\
\text { AM200 }(n=6) \\
\text { Mean } \pm \text { SD }\end{array}$ \\
\hline Cholesterol (mg/dL) & $44.14 \pm 9.15$ & $46.01 \pm 9.13$ & $65.02 \pm 1.24^{*}$ & $56.75 \pm 7.52$ & $45.49 \pm 6.34^{\#}$ & $45.96 \pm 6.74^{\# \#}$ \\
\hline Trigyceride $(\mathrm{mg} / \mathrm{dL})$ & $61.23 \pm 3.07$ & $70.48 \pm 5.7$ & $86.33 \pm 12.2 *$ & $64.37 \pm 7.13$ & $47.14 \pm 8.22^{\#}$ & $71.05 \pm 4.49^{\# \#}$ \\
\hline
\end{tabular}

Notes: ${ }^{*} p<0.05 \mathrm{HF} / \mathrm{HG} / \mathrm{STZ}$ vs control and control-treated with alpha-mangostin. ${ }^{\#} p<0.05 \mathrm{HF} / \mathrm{HG} / \mathrm{STZ}$ vs HF/HG/STZ + AM I00. ${ }^{\# \#} p<0.05$ HF/HG/STZ vs HF/HG/STZ + AM 200. Results are represented as mean \pm SD and were analyzed using one-way ANOVA followed by Tukey's post-hoc analysis. Values are considered significantly different at $p<0.05$. 


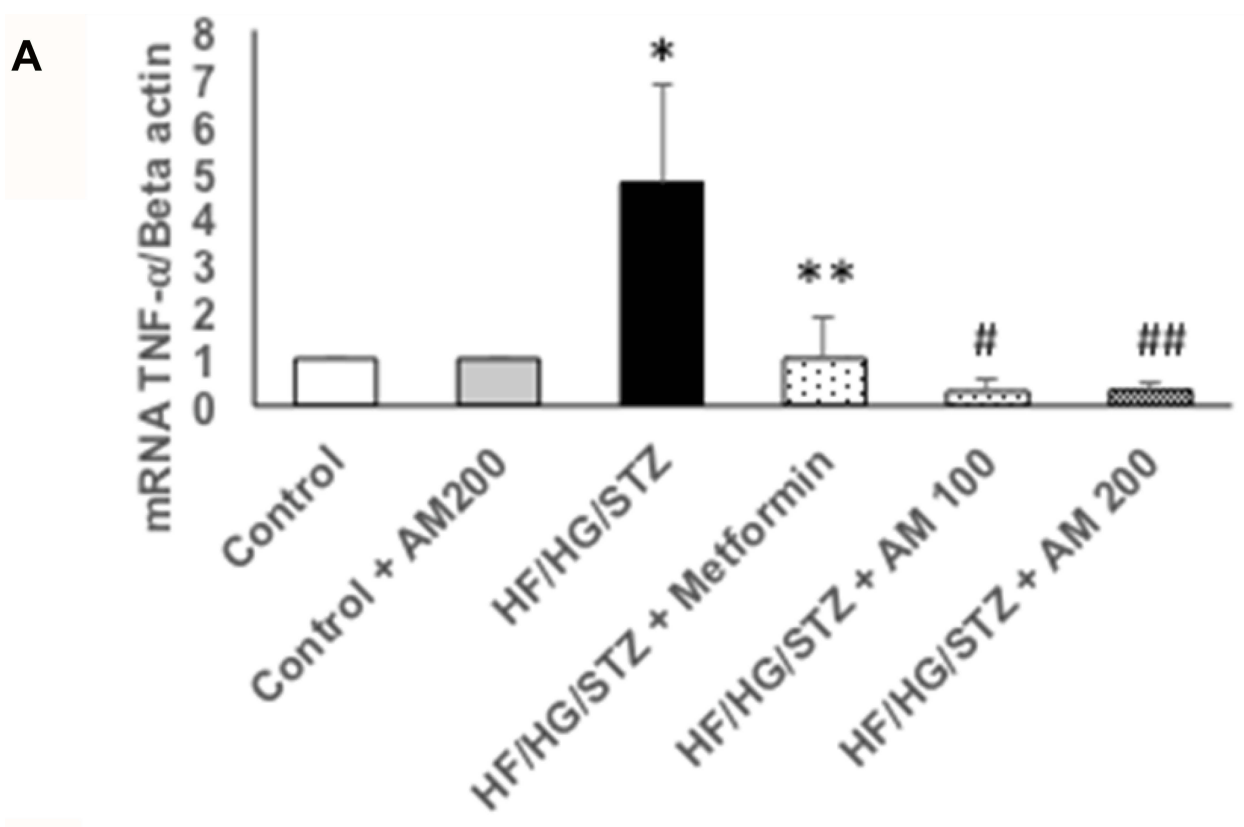

B

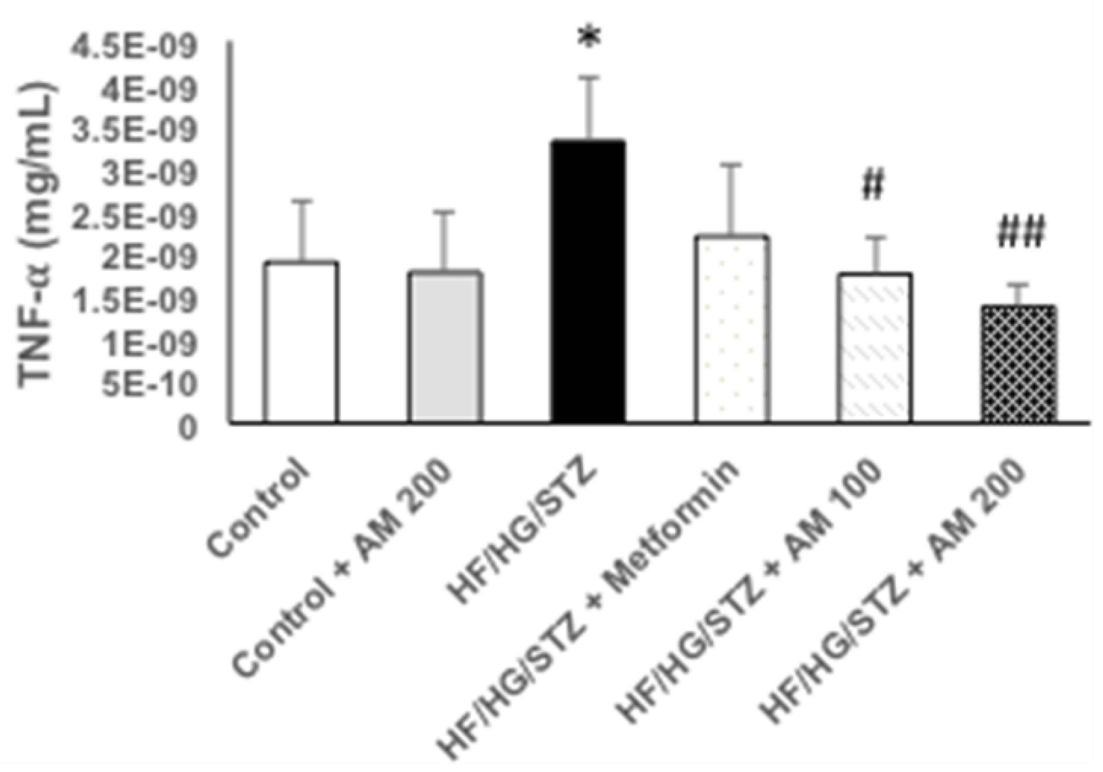

Figure I Effects of alpha-mangostin on gene and protein expression of TNF- $\alpha$. (A) Real-time PCR analysis shows that HF/HG/STZ-induced T2DM up-regulated the TNF- $\alpha$ mRNA, which was downregulated by the administration of alpha-mangostin in both doses and metformin. (B) ELISA analysis shows that HF/HG/STZ-induced T2DM upregulated the TNF- $\alpha$ protein expression, which was downregulated by the administration of alpha-mangostin in both doses and metformin. Data are presented as mean \pm $\mathrm{SD}(\mathrm{n}=6)$, and were analyzed using one-way ANOVA followed by Tukey's post-hoc analysis. Values are considered significantly different at $p<0.05$. $* p<0.05 \mathrm{HF} / \mathrm{HG} / \mathrm{STZ}$ vs control and control-treated with alpha-mangostin. ${ }^{* *} p<0.05 \mathrm{HF} / \mathrm{HG} / \mathrm{STZ}$ vs HF/HG/STZ + Metformin. ${ }^{\#} p<0.05 \mathrm{HF} / \mathrm{HG} / \mathrm{STZ}$ vs HF/HG/STZ + AM I00. ${ }^{{ }^{*}} p<0.05 \mathrm{HF} / \mathrm{HG} /$ STZ vs HF/HG/STZ + AM 200.

$\mathrm{HF} / \mathrm{HG} / \mathrm{STZ}$ administration compared to the control group, this difference did not reach a significant result (Figure 3D, $\mathrm{F}$ and $\mathrm{G}$ ). Extensive fibrosis was also seen in the $\mathrm{HF} / \mathrm{HG} /$ STZ group (Figure 4C) compared to the control and control treated with alpha-mangostin groups (Figure 4A and B), which apparently improved by administration of metformin and alpha-mangostin (Figure 4D-F).

\section{Discussion}

Many studies have reported that feeding high-fat and highglucose continued by injection of low-dose streptozotocin (HF/HG/STZ) in experimental animals can cause insulin resistance and the development of type 2 diabetes mellitus. ${ }^{19-21}$ Insulin resistance, which is a predisposing factor for atherogenic disease can cause various kinds of diseases in 
A

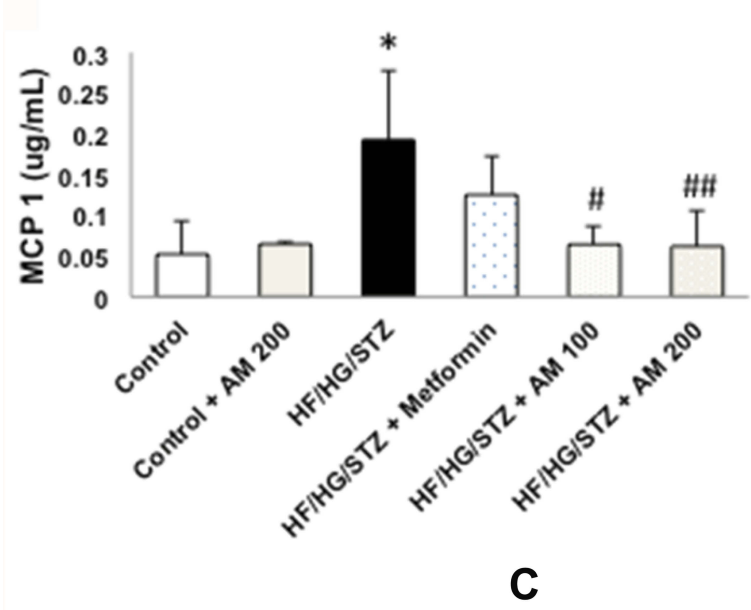

\section{B}

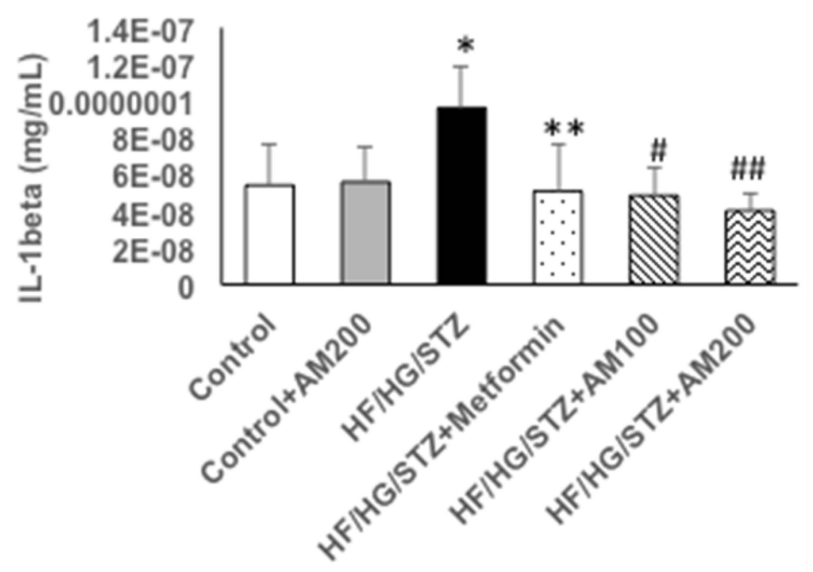

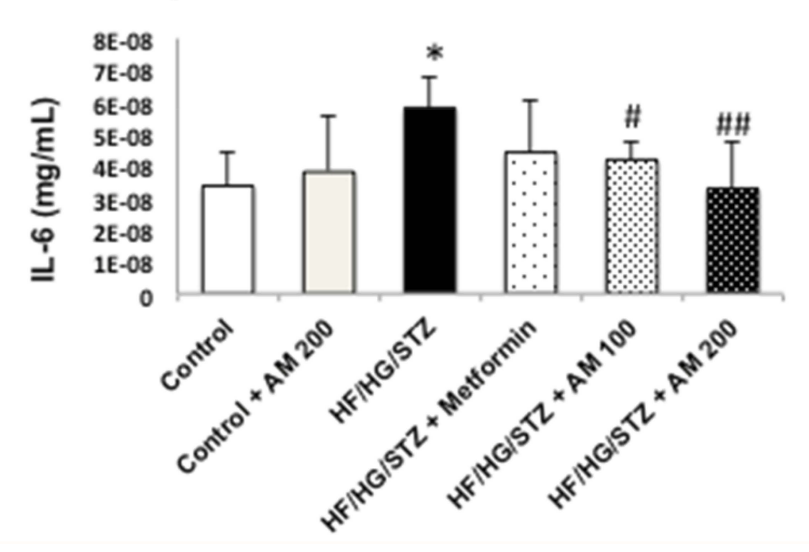

Figure 2 Effects of alpha-mangostin on protein expression of MCP-I, IL-I $\boldsymbol{\beta}$, and IL-6. ELISA analysis shows that HF/HG/STZ-induced T2DM upregulated the (A) MCP-I, (B) IL-I $\boldsymbol{\beta}$, and (C) IL-6 protein expression, which were downregulated by the administration of alpha-mangostin in both doses and metformin. Data are presented as mean \pm SD $(n=6)$, and were analyzed using one-way ANOVA followed by Tukey's post-hoc analysis. Values are considered significantly different at $p<0.05$. $* p<0.05 \mathrm{HF} / \mathrm{HG} / \mathrm{STZ}$ vs control and control-treated with alpha-mangostin. ${ }^{* *} p<0.05 \mathrm{HF} / \mathrm{HG} / \mathrm{STZ}$ vs HF/HG/STZ + Metformin. ${ }^{*} p<0.05 \mathrm{HF} / \mathrm{HG} / \mathrm{STZ}$ vs HF/HG/STZ + AM I00. ${ }^{\# \#}<0.05 \mathrm{HF} / \mathrm{HG} /$ STZ vs HF/HG/STZ + AM 200.

humans such as hypertension, type 2 diabetes mellitus, cardiovascular disease, hypertriglyceridemia, obesity, and weight gain. Therefore, reducing endogenous insulin levels is a very important step to overcome diseases related to insulin resistance. $^{22,23}$ Similar to previous studies, we have also demonstrated that feeding high-fat and high-glucose for 8 weeks and low-dose STZ injection (HF/HG/STZ) caused an increase in plasma glucose levels and insulin resistance as indicated by the HOMA-IR values. In addition to an increase in plasma glucose levels and insulin resistance, we also proved that $\mathrm{HF} / \mathrm{HG} / \mathrm{STZ}$ rats also showed hypertriglyceridemia, hypercholesterolemia, hypertension, and cardiac hypertrophy and fibrosis, which are manifestations of type 2 diabetes mellitus. The main finding of the present study was that the administration of alpha-mangostin at doses of 100 and $200 \mathrm{mg} / \mathrm{kg}$ /day not only improved cardiac hypertrophy and fibrosis but also attenuated the increase of associated biochemical parameters induced by $\mathrm{HF} / \mathrm{HG} / \mathrm{STZ}$.
Diabetes is associated with an excessive muscle wasting and tissue loss due to the unavailability of carbohydrates as a source of energy in diabetes. ${ }^{21}$ In the present study, we demonstrated that the $\mathrm{HF} / \mathrm{HG} / \mathrm{STZ}$ rats' body weight appeared lower when compared to the control group, though food intake was higher in the $\mathrm{HF} / \mathrm{HG} / \mathrm{STZ}$ rats. However, alpha-mangostin and metformin administration restored the body weight to near normalcy. We also have shown that administration of alpha-mangostin can improve HOMA-IR similar to metformin which showed that alpha-mangostin can improve insulin sensitivity with the result of a decreased plasma glucose levels.

Previous studies have reported that diabetes is associated with elevated levels of AST, ALT, BUN, and uric acid in serum of diabetics and is closely related to the increasing of complications of diabetes such as cardiomyopathy. ${ }^{24-27}$ Vozarova et al (2002) proved that high levels of ALT in serum are associated with decreased hepatic insulin 

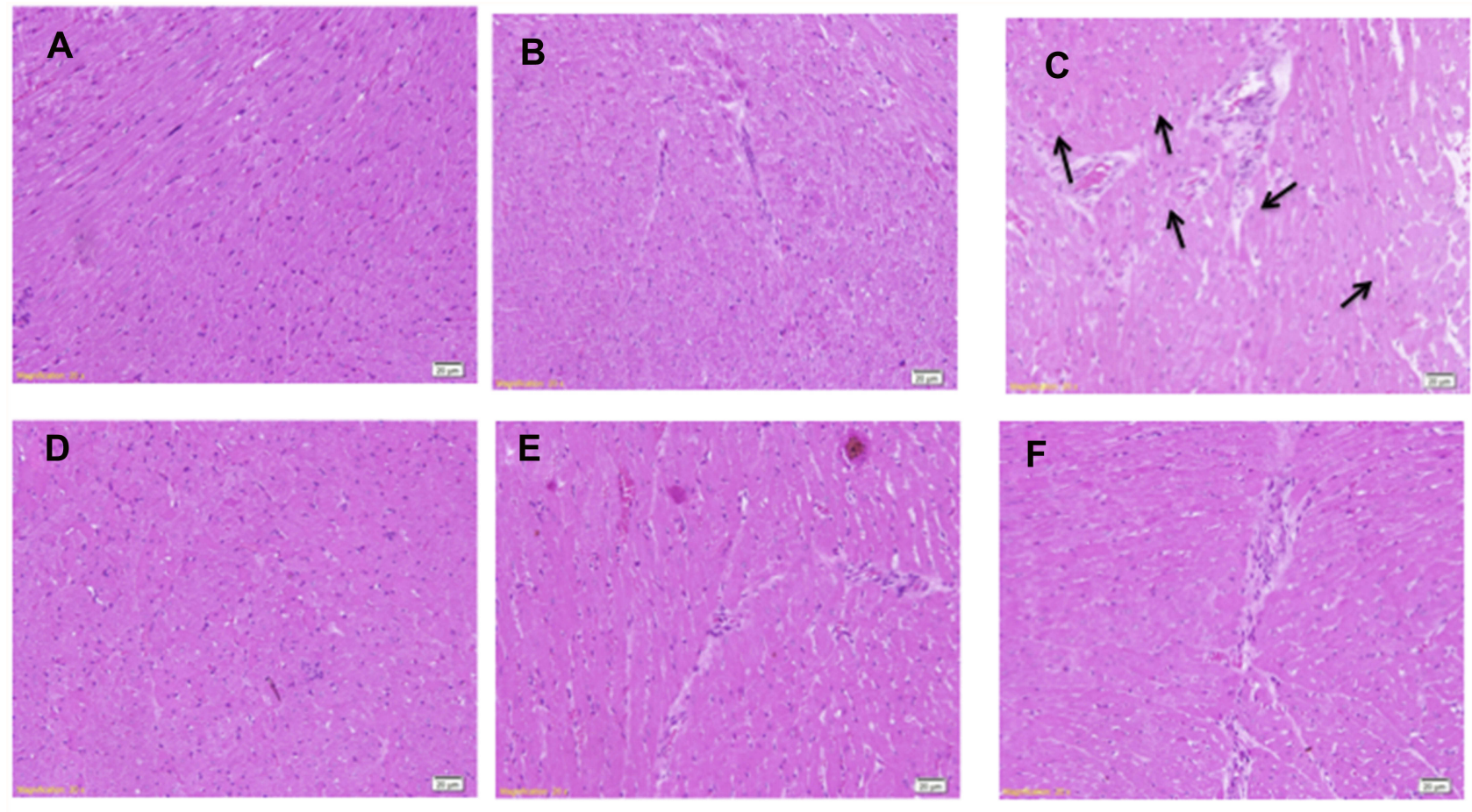

\section{G}

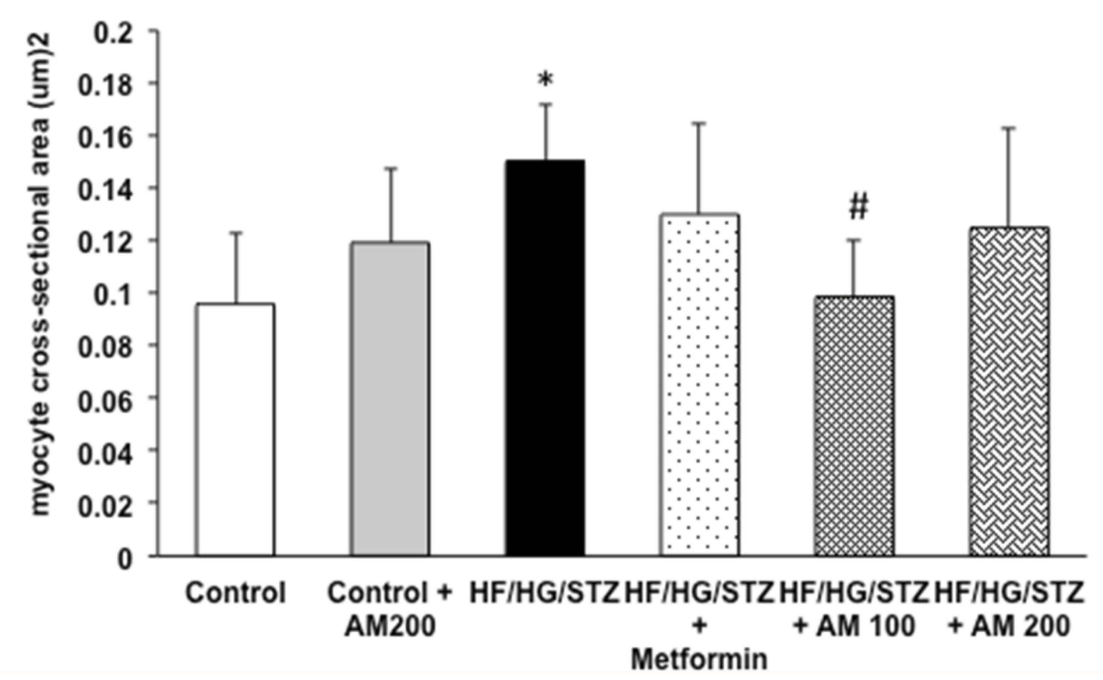

Figure 3 Effects of alpha-mangostin on histopathological changes. (A-F) Hematoxylin and eosin staining of the cross-sectional tissue slices of left ventricular depicting cardiomyocyte hypertrophy (×200). (A) control; (B) control-treated with AM 200; (C) HF/HG/STZ; (D) HF/HG/STZ + Metformin; (E) HF/HG/STZ + AM I00; (F) HF/HG/ STZ + AM 200. Arrows in (C) indicate cardiomyocyte hypertrophy. (G) Bar graph shows quantitative analysis of cross-sectional area. Results are represented as mean \pm SD and were analyzed using one-way ANOVA followed by Tukey's post-hoc analysis. Values are considered significantly different at $p<0.05$. ${ }^{*} p<0.05 \mathrm{HF} / \mathrm{HG} / \mathrm{STZ}$ vs control and control-treated with alpha-mangostin. ${ }^{\#} p<0.05 \mathrm{HF} / \mathrm{HG} / \mathrm{STZ}$ vs HF/HG/STZ + AM 100.

sensitivity. ${ }^{28}$ Ghimire et al (2018) also described significant increase in ALT and AST among patients with diabetes mellitus; hence appropriate diagnosis and management of the abnormal liver parameters may avoid liver-related morbidity and mortality in diabetic population. ${ }^{29}$ In fact, insulin resistance will cause lipolysis, thereby causing accumulation of non-esterified fatty acids, which is known to be directly toxic to hepatocytes which will further increase serum transaminases and decrease the capacity of synthesis in the liver. ${ }^{30}$ Elevated activities of serum aminotransaminases are also a common signal of cardiovascular disease observed in people with diabetes. ${ }^{31}$ Besides increasing serum AST and ALT levels that have been reported to increase the incidence of cardiovascular disease, an increase in serum uric acid and 
BUN is also an independent risk factor for cardiovascular disease and metabolic syndrome. ${ }^{5,6}$ Chen et al (2016) suggested that serum uric acid levels might be an important risk factor for elevated ALT. ${ }^{5}$ In fact, insulin resistance not only causes hyperinsulinemia, which in turn leads to decreased serum uric acid renal excretion but also makes hepatocytes vulnerable to damage as it is shown by increase in serum transaminases. $^{32,33}$ Recently, Lee JH (2019) reported that hyperuricemia is also associated with hypertension in children and adolescents. ${ }^{34}$ From the above results, it can be concluded that there is an association between hyperuricemia and increased serum transaminases with an increased risk of cardiovascular disorders in diabetics. Similar to previous studies, we also demonstrated that HF/HG/STZ caused an increase in serum AST, ALT, uric acid, and BUN as compared to the control and control-treated with alpha-mangostin groups. The elevation of serum AST, ALT, uric acid, and BUN levels caused by $\mathrm{HF} / \mathrm{HG} / \mathrm{STZ}$ was declined after the administration of alpha-mangostin and metformin. The stabilization of these enzyme levels and renal parameters by the alpha-mangostin was an obvious indication of the improvement of the functional status of the liver and kidney.

Changes in plasma lipid concentrations, namely, hypertriglyceridemia and hypercholesterolemia are also the most frequent complications leading to cardiovascular disease in patients with diabetes mellitus. ${ }^{4}$ In the present study, we demonstrated that while the serum total cholesterol and triglyceride were significantly increased in the $\mathrm{HF} / \mathrm{HG} /$ STZ group, alpha-mangostin and metformin administration lowered them. Indeed, the cause of hypertriglyceridemia and hypercholesterolemia is due to insulin resistance in adipose tissue leads to an increase in intracellular triglycerides hydrolysis and release of fatty acids into the circulation. $^{22}$

Many studies have proven that diabetes is closely related to myocardial fibrosis and cardiomyocyte
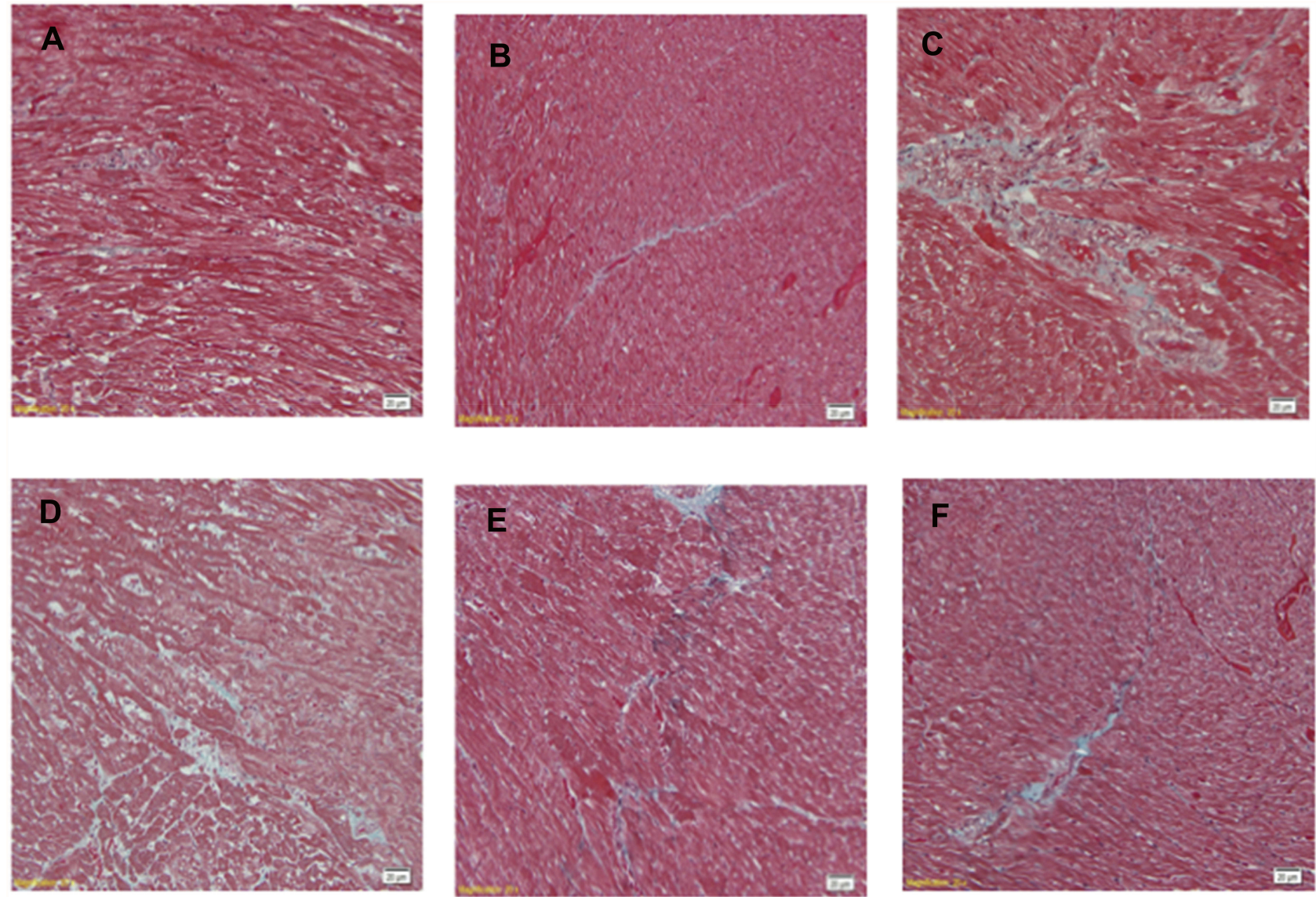

Figure 4 Effects of alpha-mangostin on cardiac fibrosis. (A-F) Masson's trichrome staining for fibrosis of the cross-sectional tissue slices of left ventricular. Fibrosis is indicated by blue area as opposed to the red myocardium $(\times 200)$. HF/HG/STZ administration for II weeks markedly enhanced fibrotic tissue in myocardium [C]. Treatment with metformin and alpha mangostin [D-F] reduced the fibrotic tissue in myocardium similar to that in control rats [A and $\mathbf{B}$ ]. 
hypertrophy. Myocardial fibrosis are also often found in cardiac magnetic resonance imaging examinations in patients with diabetes without a history of previous myocardial infarction; this illustrates the presence of silent coronary events in diabetics. $^{35,36}$ One of the causes of cardiac fibrosis in diabetics is activation of immune pathway and induction of proinflammatory cytokines. ${ }^{37}$ The infiltration of inflammatory cells into cardiomyocyte will trigger hypertension, atherosclerosis, myocardial ischemia, and chronic heart failure, ${ }^{38}$ which in turn involved in heart tissue damage and significantly induce cardiac dysfunction. $^{39}$ In fact, hyperglycemia is considered to be a major factor in the occurrence of low-grade inflammation in diabetes mellitus. This inflammation will then induce overexpression of cytokines including TNF- $\alpha$ and MCP$1 .^{38,40}$ In the present study, we showed an increased in LVW-to-BW ratio in the $\mathrm{HF} / \mathrm{HG} / \mathrm{STZ}$ group which indicate cardiac hypertrophy which was confirmed also with histopathology examination as an elevated in the size of the myocyte cross-sectional area, while after administration of alpha-mangostin as well as metformin, the above signs were improved, though only alpha-mangostin at a dose of $100 \mathrm{mg} / \mathrm{kg} /$ day which show a significant difference as compared to that of $\mathrm{HF} / \mathrm{HG} / \mathrm{STZ}$ group, which indicate that there is no dose-dependency of alpha-mangostin in the process of cardiac fibrosis and hypertrophy. We also observed an increase in blood pressure in the HF/HG/STZ group significantly compared with control and controltreated with alpha-mangostin groups, and reduced significantly by alpha-mangostin in both doses and metformin. To explore the presence or absence of fibrosis in the heart, we did a histopathological examination with Masson's trichrome staining. We observed that fibrosis as shown by blue area compared to red area was more extensive in the $\mathrm{HF} / \mathrm{HG} / \mathrm{STZ}$-induced diabetic group compared to that control and control-treated with alpha-mangostin groups. Interestingly, the administration of alpha-mangostin and metformin could reduce the fibrosis in the heart. Evaluation of cardiac enzymes is essential in case of diabetic cardiomyopathy. Biomarkers that are often used to assess cardiac damage include CK-MB and LDH. CK-MB serum is a sensitive indicator in the early stages of cardiac damage, whereas LDH will increase when further cardiac damage occurs. ${ }^{41}$ In this study, administration of alphamangostin in both doses and metformin significantly reduced levels of CK-MB, but not $\mathrm{LDH}$. This shows that cardiac damage that occurs is still in early stages. The above results proved that alpha-mangostin has a protective effect not only on cardiac hypertrophy but also on cardiac fibrosis to some extent.

Accumulating lines of evidence have shown that lowgrade inflammation plays an important role in the occurrence and development of cardiovascular disease in diabetics. ${ }^{37,39}$ It has proven that diabetes is associated with an inflammatory response including increased expression of TNF- $\alpha$ and MCP1 in adipose tissues and lumen of blood vessels. ${ }^{42}$ Additionally, TNF- $\alpha$ has been reported to elevate MCP-1 expression, therefore the interaction between the two increases the development of vascular dysfunction in diabetics. ${ }^{43}$ Yang et al (2009) have demonstrated that administration of neutralizing antibody to TNF- $\alpha$ and MCP-1 in genetically modified mice with type 2 diabetes could reduce the expression of adhesion molecules which showed that there was an interaction of proinflammatory cytokines to strengthens signaling process that leads to vascular dysfunction. $^{42}$ In the present study, the expressions of TNF$\alpha, \mathrm{MCP}-1, \mathrm{IL}-1 \beta$, and IL-6 in myocardial tissue of HF/HG/ STZ-induced diabetic rats' hearts were remarkably upregulated and those expressions could be inhibited by the administration of alpha-mangostin in both doses and metformin. Similar to previous studies that have demonstrated that alpha-mangostin has an anti-inflammatory effect, ${ }^{4,45}$ our results also exhibited that alpha-mangostin has this effect on myocardial tissue of diabetic rats induced by high-fat /high-glucose and low-dose injection of STZ.

\section{Conclusions}

The results of the present study clearly indicate that administration of alpha-mangostin and metformin to $\mathrm{HF} /$ $\mathrm{HG} / \mathrm{STZ}$-induced diabetic rats increased insulin sensitivity, improved cardiac hypertrophy and fibrosis, and related biochemical parameters and these effects may be through alleviating inflammatory process. Further, comprehensive studied are still needed to explore biochemical and pharmacological investigations to reveal the molecular mechanism of action of alpha-mangostin.

\section{Acknowledgments}

We would like to thank all biotechnicians, especially Chiswyta, of the clinical laboratory and provincial key laboratory of the Clinical Pharmacology Laboratory and Integrated Laboratory in Universitas Indonesia for their technical support. This work was supported by the Ministry of Research, Technology and Higher Education of Indonesia (Grant number: 1/E1/KP.PTNBH/2019 and 234/PKS/R/UI/2019). 


\section{Disclosure}

Mr Fabrian Charlie reports grants from PITTA UI during the conduct of the study. The authors report no other conflicts of interest in this work.

\section{References}

1. De Rosa S, Arcidiacono B, Chiefari E, et al. Type 2 diabetes mellitus and cardiovascular disease: genetic and epigenetic links. Front Endocrinol (Lausanne). 2018;17(9):2. doi:10.3389/fendo.2018.00002

2. Stumvoll M, Goldstein BJ, van Haeften TW. Type 2 diabetes: principles of pathogenesis and therapy. Lancet. 2005;365 (9467):1333-1346. doi:10.1016/S0140-6736(05)61032-X

3. Vecchié A, Montecucco F, Carbone F, et al. Diabetes and vascular disease: is it all about glycemia? Curr Pharm Des. 2019;25 (29):3112-3127. doi:10.2174/1381612825666190830181944

4. Jia G, Hill MA, Sowers JR. Diabetic cardiomyopathy: an update of mechanisms contributing to this clinical entity. Circ Res. 2018;122 (4):624-638. doi:10.1161/CIRCRESAHA.117.311586

5. Chen S, Guo X, Chen Y, et al. Prevalence of abnormal serum liver enzymes in patients with type 2 diabetes mellitus: a cross-sectional study from China. Postgrad Med. 2016;128(8):770-776. doi:10.1080/ 00325481.2016 .1242366

6. Feig DI, Kang DH, Johnson RJ. Uric acid and cardiovascular risk. $N$ Engl $J$ Med. 2008;359(17):1811-1821. doi:10.1056/NEJMra08 00885

7. Bell DS. Heart failure: the frequent, forgotten, and often fatal complication of diabetes. Diabetes Care. 2003;26(8):2433-2441. doi:10. 2337/diacare.26.8.2433

8. Ferrannini E, Cushman WC. Diabetes and hypertension: the bad companions. Lancet. 2012;380(9841):601-610. doi:10.1016/S01406736(12)60987-8

9. Hunking P. Lifestyle advice in preventing and treating type 2 diabetes. J Fam Health. 2005;16:109e12.

10. Milajerdi A, Jazayeri S, Hashemzadeh N, et al. The effect of saffron (Crocus sativus L.) hydroalcoholic extract on metabolic control in type 2 diabetes mellitus: a triple-blinded randomized clinical trial J Res Med Sci. 2018;23:16. doi:10.4103/jrms.JRMS_286_17

11. World Health Organization (WHO). The WHO expert committee on diabetes mellitus, Technical Report Series 646. Geneva, Switzerland; 1980.

12. Keputusan Menteri Kesehatan Republik Indonesia Nomor 0584/ Menkes/SK/VI/1995 Tentang Sentra Pengembangan dan Penerapan Pengobatan Tradisional; 1995.

13. Laksmiani NPL. Ethanolic extract of mangosteen (Garcinia mangostana) pericarp as sensitivity enhancer of doxorubicin on MCF-7 cells by inhibiting P-glycoprotein. Nus Biosci. 2019;11(1):49-55.

14. Adenina S, Rahmaniah R, Yuyuntia Y, et al. The effect of alphamangostin on transforming growth factor beta 1 (TGF- $\beta 1$ ) and matrix metalloproteinase-3 expression in TGF- $\beta$-induced hepatic stellate cells. Int J App Pharm. 2019;11(1):177-180. doi:10.22159/ijap.2019. v11s1.16144

15. Chen LG, Yang LL, Wang CC. Anti-inflammatory activity of mangostins from Garcinia mangostana. Food Chem Toxicol. 2008;46 (2):688-693. doi:10.1016/j.fct.2007.09.096

16. Pedraza-Chaverrí J, Reyes-Fermín LM, Nolasco-Amaya EG, et al. ROS scavenging capacity and neuroprotective effect of $\alpha$-mangostin against 3-nitropropionic acid in cerebellar granule neurons. Exp Toxicol Pathol. 2009;61(5):491-501. doi:10.1016/j.etp.2008.11.002

17. Matthews DR, Hosker JP, Rudenski AS, et al. Homeostasis model assessment: insulin resistance and beta-cell function from fasting plasma glucose and insulin concentrations in man. Diabetologia. 1985;28(7):412-419. doi:10.1007/BF00280883
18. Livak KJ, Schmittgen TD. Analysis of relative gene expression data using real-time quantitative PCR and the 2(-Delta Delta C(T)) method. Methods. 2001;25:402-408. doi:10.1006/meth.2001.1262

19. Mekseepralard C, Areebambud C, Suksamrarn S, et al. Effects of long-term alpha-mangostin supplementation on hyperglycemia and insulin resistance in type 2 diabetic rats induced by high fat diet and low dose streptozotocin. J Med Assoc Thai. 2015;98(Suppl 10): S23-S30.

20. Jariyapongskul A, Areebambud C, Suksamrarn S, et al. Alphamangostin attenuation of hyperglycemia-induced ocular hypoperfusion and blood retinal barrier leakage in the early stage of type 2 diabetes rats. Biomed Res Int. 2015;2015:785826. doi:10.1155/2015/ 785826

21. Gothandam K, Ganesan VS, Ayyasamy T, et al. Antioxidant potential of theaflavin ameliorates the activities of key enzymes of glucose metabolism in high fat diet and streptozotocin-induced diabetic rats. Redox Rep. 2019;24(1):41-50. doi:10.1080/13510002.2019.1624085

22. Ginsberg HN. Insulin resistance and cardiovascular disease. J Clin Invest. 2000;106(4):453-458. doi:10.1172/JCI10762

23. Grundy SM, Hansen B, Smith SC, et al. Clinical management of metabolic syndrome: report of the American Heart Association/ National Heart, Lung, and Blood Institute/American Diabetes Association conference on scientific issues related to management. Arterioscler Thromb Vasc Biol. 2004;24(2):e19-e24. doi:10.1161/01. ATV.0000112379.88385.67

24. Singh N, Kamath V, Rajini PS. Attenuation of hyperglycemia and associated biochemical parameters in STZ-induced diabetic rats by dietary supplementation of potato peel powder. Clin Chim Acta. 2005;353(1-2):165-175. doi:10.1016/j.cccn.2004.10.016

25. Bratoeva K, Stoyanov GS, Merdzhanova A, et al. Manifestations of renal impairment in fructose-induced metabolic syndrome. Cureus. 2017;9(11):e1826.

26. Buettner R, Parhofer KG, Woenckhaus M, et al. Defining high-fatdiet rat models: metabolic and molecular effects of different fat types. J Mol Endocrinol. 2006;36(3):485-501. doi:10.1677/jme.1.01909

27. Oliveira GO, Braga CP, Fernandes AA. Improvement of biochemical parameters in type 1diabetic rats after the roots aqueous extract of yacon [Smallanthus sonchifolius (Poepp.\& Endl.)] treatment. Food Chem Toxicol. 2013;59:256-260. doi:10.1016/j.fct.2013.05.050

28. Vozarova B, Stefan N, Lindsay RS, et al. High alanine aminotransferase is associated with decreased hepatic insulin sensitivity and predicts the development of type 2 diabetes. Diabetes. 2002;51 (6):1889-1895. doi:10.2337/diabetes.51.6.1889

29. Ghimire S, Shakya S, Shakya J. Abnormal liver parameters among individuals with type 2 diabetes mellitus Nepalese population. Biochem Pharmacol (Los Angel). 2018;7:1. doi:10.4172/21670501.1000243

30. Judi L, Toukan A, Khader Y, et al. Prevalence of elevated hepatic transaminases among Jordanian patients with type 2 diabetes mellitus. Ann Saudi Med. 2010;30(1):25-32. doi:10.5144/0256-4947.59369

31. Arkkila PE, Koskinen PJ, Kantola IM, et al. Diabetic complications are associated with liver enzyme activities in people with type 1 diabetes. Diabetes Res Clin Pract. 2001;52(2):113-118. doi:10.10 16/S0168-8227(00)00241-2

32. Quiñones Galvan A, Natali A, Baldi S, et al. Effect of insulin on uric acid excretion in humans. Am J Physiol. 1995;268(1 Pt 1):E1-E5. doi:10.1152/ajpendo.1995.268.1.E1

33. Choi SS, Diehl AM. Hepatic triglyceride synthesis and nonalcoholic fatty liver disease. Curr Opin Lipidol. 2008;19(3):295-300. doi:10.1097/MOL.0b013e3282ff5e55

34. Lee JH. Prevalence of hyperuricemia and its association with metabolic syndrome and cardiometabolic risk factors in Korean children and adolescents: analysis based on the 2016-2017 Korea National Health and Nutrition Examination Survey. Korean J Pediatr. 2019;62 (8):317-323. doi:10.3345/kjp.2019.00444 
35. Kwong RY, Sattar H, Wu H, et al. Incidence and prognostic implication of unrecognized myocardial scar characterized by cardiac magnetic resonance in diabetic patients without clinical evidence of myocardial infarction. Circulation. 2008;118(100):1011-1020. doi:10.1161/CIRCULATIONAHA.107.727826

36. Turkbey EB, Backlund JY, Genuth S, et al. DCCT/EDIC Research Group. Myocardial structure, function, and scar in patients with type 1 diabetes mellitus. Circulation. 2011;124(16):1737-1746. doi:10.1 161/CIRCULATIONAHA.111.022327

37. Russo I, Frangogiannis NG. Diabetes-associated cardiac fibrosis: cellular effectors, molecular mechanisms and therapeutic opportunities. J Mol Cell Cardiol. 2016;90:84-93. doi:10.1016/j.yjmcc.2015.12.011

38. Nikolajević Starčević J, Janić M, Šabovič M. Molecular mechanisms responsible for diastolic dysfunction in diabetes mellitus patients. Int J Mol Sci. 2019;9(5):20.

39. Bienvenu LA, Morgan J, Rickard AJ, et al. Macrophage mineralocorticoid receptor signaling plays a key role in aldosterone-independent cardiac fibrosis. Endocrinology. 2012;153(7):3416-3425. doi:10.1210/ en.2011-2098

40. Jia G, DeMarco VG, Sowers JR. Insulin resistance and hyperinsulinaemia in diabetic cardiomyopathy. Nat Rev Endocrinol. 2016;12 (3):144-153. doi:10.1038/nrendo.2015.216
41. Badole SL, Chaudhari SM, Jangam GB, et al. Cardioprotective activity of pongamia pinnata in streptozotocin-nicotinamide induced diabetic rats. Biomed Res Int. 2015;2015:403291. doi:10.1155/2015/ 403291

42. Yang J, Park Y, Zhang H, et al. Role of MCP-1 in tumor necrosis factor-alpha-induced endothelial dysfunction in type 2 diabetic mice. Am J Physiol Heart Circ Physiol. 2009;297(4):H1208-H1216. doi:10.1152/ajpheart.00396.2009

43. Hotamisligil GS, Shargill NS, Spiegelman BM. Adipose expression of tumor necrosis factor-alpha: direct role in obesity-linked insulin resistance. Science. 1993;259(5091):87-91. doi:10.1126/science.7678183

44. Sampath PD, Vijayaragavan K. Ameliorative prospective of alpha-mangostin, a xanthone derivative from Garcinia mangostana against beta-adrenergic catecholamine-induced myocardial toxicity and anomalous cardiac TNF-alpha and COX-2 expressions in rats. Exp Toxicol Pathol. 2008;60(4-5):357-364. doi:10.1016/j.etp.2008.02.006

45. Xu Y, Zhou H, Cai L. Alpha-mangostin attenuates oxidative stress and inflammation in adjuvant-induced arthritic rats. Trop $J$ Pharm Res. 2017;16(11):2611-2616. doi:10.4314/tjpr.v16i11.6

\section{Publish your work in this journal}

The Journal of Experimental Pharmacology is an international, peerreviewed, open access journal publishing original research, reports, reviews and commentaries on all areas of laboratory and experimental pharmacology. The manuscript management system is completely online and includes a very quick and fair peer-review system. Visit http://www.dovepress.com/testimonials.php to read real quotes from published authors. 